\title{
Cause Analysis and Countermeasure of Gypsum Rain in Coal-fired Power Plants
}

\section{Qizhen Liu, Yanjing Sun, Yi Sun}

Shanghai Environmental Monitoring Centre, 200030.

Received 2013

\begin{abstract}
Focusing on the phenomenon of gypsum rain while wet desulphurization(WFGD) were adopted in coal fired power plant without GGH, the paper studied and put forward the solutions: 1) desulfurization facilities related equipment modification; 2) optimal operation of existing desulfurization facilities.
\end{abstract}

Keywords: Coal Fired Power Plant; Gypsum Rain; GGH; Wet Desulphurization

\section{Introduction}

Currently, we have already completed the inspection of desulfurization units of coal-fired power plants with 14.24 million kilowatts (about $96 \%$ of the total capacity of installed coal-fired units). The Desulfurization units are mainly based on limestone/gypsum wet FGD, only 8 sets are installed GGH, which accounts for $15 \%$ of total capacity.

The desulphurization system without GGH has a lower exhaust temperature because of the lack of stack reheating measures, so that flue gas cannot quickly dissipate, going with the inefficient uplift and spread, resulted by the net smoke with saturated water of absorption tower export partly condensing to form droplets in the discharge process. Especially for adverse weather conditions like low temperature and low pressure, the gas will form condensed into drops when leaving chimney, falling down to the ground around the chimney like rain, leaving solid white residues after landing and polluting the surrounding environment of power plant. That is the so-called "gypsum rain”.(Figure 1)

\section{Investigation and Cause Analysis of “Gypsum rain”}

Through the in-depth investigation of six power plants in Shanghai, it is found that "gypsum rain" phenomenon is mainly affected by the following factors.

\subsection{External Causes}

The gypsum rain is not conducive to spread in steady state conditions. When the temperature is low, it is easy to form droplets and the probability of particle coagulation also increases.

\subsection{Internal Reasons}

The internal reason includes excessive high gas flow and speed; low efficiency of defogger; and the low temperature of exhaust flue gas.

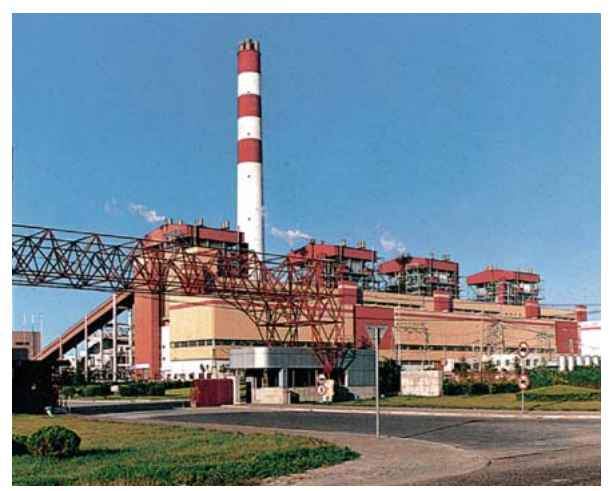

(a)

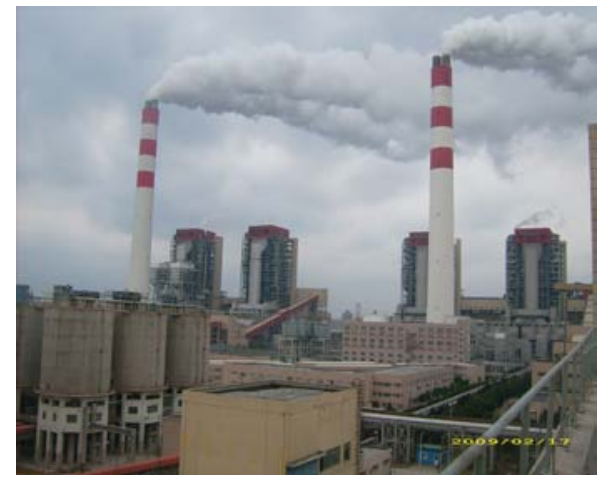

(b)

Figure 1. Installation GGH exterior effect contrast diagram. (a) With GGH- "a smoke-free look"; (b) No GGH -"white 
smoke billowing".

- Excessive high speed of flue gas when passing the desulfurization precipitator

When the unit is running in the high load operation, the excessive high gas flow results in the increasing capacity of carrying gypsum slurry.

- The uneven distribution of imported gas

The smoke distributes unevenly when coming out from the absorber, which results in the uneven flow in the defogger and then increases partly defogger clogging. In that case, flue gas flow channel becomes smaller, smoke-speed increases, and the ability to carry gypsum slurry is further strengthened.

- The low temperature of flue gas at desulfurization export

The flue gas temperature going into the absorption tower is $100^{\circ} \mathrm{C}-130^{\circ} \mathrm{C}$ while the temperature out after through the desulfurization absorber is $60^{\circ} \mathrm{C}-70^{\circ} \mathrm{C}$. The temperature will be further decreased to about $50^{\circ} \mathrm{C}$ after water washing in the 2-level defogger, which will shorter the climbing distance after smoke leaving the chimney and then make it condense into droplets rapidly and fall to the ground.

Except the above-mentioned three main factors, factors such as absorber liquid level, limestone slurry $\mathrm{pH}$, original content of PM in the flue gas will also affect the carrying amount of liquid among flue gas [1].

\section{Preliminary Analysis of the Composition of "Gypsum Rain"}

Considering that the traditional drop bucket method of collecting gypsum rain can only get few sample for composition analysis. Experts of desulfurization technology suggest that: as part of the flue gas condensing and back-flowing on the wall of the chimney, and then forming a backflow consisted with the same composition as "gypsum Rain" is, we collected the backflow fluid on Shanghai power plant A's chimney wall and analyzed its composition. Statistics show that the $\mathrm{pH}$ of "Gypsum rain" filtrate is about 2.6 which means a strong acidity. All kinds of ionic components analysis show that sulfate concentra- tion in the filtrate reached a maximum of $774 \mathrm{mg} / \mathrm{L}$, followed by sodium, $125 \mathrm{mg} / \mathrm{L}$, while the calcium component is only $14.0 \mathrm{mg} / \mathrm{L}$. The particle is mainly made up of oxidation silicon, followed by about $23.7 \%$ calcium oxide and $13.0 \%$ sulfur. Therefore, it can be seen that the acidity of "Gypsum rain" is relatively strong, which affects the surroundings seriously and causes severe corrosion. The main particles of "Gypsum rain” are small dust and smoke particles. At the same time, "Gypsum rain” also contains much limestone or gypsum.(Figure 2)

\section{The Method to Solve “Gypsum Rain”}

There are few reports about “Gypsum Rain” abroad. In early German regulations, the temperature of discharging flue gas should be higher than $72^{\circ} \mathrm{C}$. Therefore, all desulfurization facilities have installed the GGH. In 2002, German adopted the European Union standards and cancelled the temperature limitation of discharging flue gas. Then more coal fired power plant would discharge gas through the cooling tower. U.S. environmental standards has no requirements on smoke temperature of chimney exit, but some American power plant still installed cleanburning-fuel burner at the bottom of the chimney. Japan has taken high temperature smoke emissions to enhance the diffusion ability of flue gas in order to reduce the native pollution of; in that case, all the FGD devices installed the GGH in Japan [2-4].

Although there are "gypsum rain” phenomenon reported in China, in-depth study is lacked. According to the material researched and desulfurization experts, the method to solve "gypsum rain" is divided into two categories: 1) Equipment modification related to desulfurization ; 2) optimal operation of existing desulfurization facilities.

\subsection{Equipment Modification Related to Desulfurization}

- Secondary air heating boiler

We added boiler secondary air bypass at the exit of the chimney and introduced $300^{\circ} \mathrm{C}$ hot air into the second boiler. The stack mixed by bypass flue and chimney one was let out after heated.

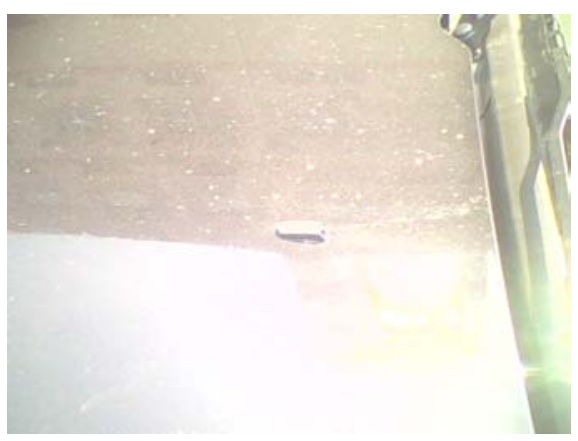

(a)

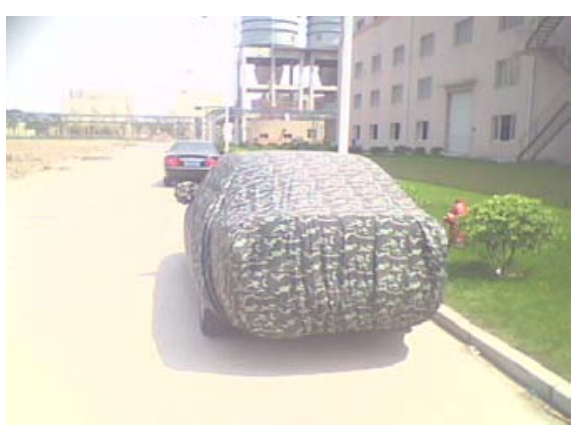

(b) 
Figture 2. the impact of "Gypsum Rain" on vehicles around power plants. (a) “White” glass; (b) Vehicles with proteciton.

- Defogger transformation

1) Addition layer of demisting facilities

At present, most desulfurization facilities use one-layer or two-layer demisting facilities. It is suggested that one layer of demisting facilities should be added in the space location allowed.

2) Addition uniform guide plate on the demister inlet horizontal flue section

According to the high speed of flue gas near the chimney wall, a guide plate should be set up in the corner outside the flue to reduce its velocity and eliminate flue gas disturbance of sprayer entrance. It makes smoke even into demisting precipitator and reduces local congestion.

3) Mist eliminator washing system transformation

At present, cold-water-rinse method is adopted in mist eliminator wishing. The method could greatly reduce the temperature of flue gas and increase "gypsum rain” phenomenon. It is suggested that vapor source should be added into the original mist eliminator washing system and a water desuperheating device be set up on pipeline, adjusting the steam temperature, in order to prevent defogger base metal from excessive steam temperature. The unit adopts the method of water washing in conjunction with steam flush in normal operation. With the steam auxiliary steam source and controlling pressure through a valve, a variable pressure flushing can be achieved.

- Addition flue gas heater

In American, considering that a unit without GGH would make the temperature too low and produce a negative impact on the surrounding environment, some power plants install clean burning fuel burner at the bottom of the chimney to temporarily heat the gas after desulfurization in adverse weather conditions. This method can protect the environment with low investment and running costs. As a kind of practical solutions, it is worth using for reference.

\section{- Installing the GGH}

Installing the GGH will be able to better solve the "gypsum rain" phenomenon; it is also conducive to long-distance gas transportation. Though it can solve local pollution problems, the investment costs are very high on one hand and, on the other hand, parts of the power plants are limited by space. Besides, GGH blockage reduces the rate of desulfurization facilities into operation drawbacks. Therefore, we recommended that it could be considered that coal-fired units could compromise GGH while installing desulfurization devices [2-4].

- Transformation of the inner chimney wall

As the lower temperature of the inner chimney wall, it is easy for slurry to condense into drops hanging on the wall and be carried out of the chimney by flue gas in the form of droplets. It is recommended that a circular blocking device should be set in the chimney to reduce the slurry carried on the chimney wall.

\subsection{Optimal Operation of Existing Desulfurization Facilities}

- Paying attention to the pressure gap of defoggers and reducing defogger jam

Higher slurry density, $\mathrm{pH}$ and liquid-gas ratio will cause defogger jam, increase the pressure of defogger and reduce the efficiency. Therefore, paying attention to the pressure gap of defoggers and controlling the slurry density, $\mathrm{pH}$ and liquid-gas ratio within reasonable ranges will decrease defogger jam and the probability to form "gypsum Rain”.

- Optimizing defogger washing and reducing the amount of slurry carried

Taking the washing order as "upper parts of secondary defogger, lower parts of secondary defogger, primary defogger upper, primary defogger lower, secondary defogger upper and secondary lower parts again”. It means firstly washing the upper part of the secondary defogger, then washing the lower part to make the secondary defogger's channel unobstructed and ease the congestion with a sudden increase in concentration of gypsum droplets into the secondary defogger. After the pressure of the seconddary defogger reduced, washing the upper and lower part of the primary defogger and then washing the secondary defogger again to remove the gypsum droplets from the primary defogger, avoiding being carried away. At the same time, pay attention to the rule of power flow. Before unit load increases, washing defogger ahead will greatly reduce carrying capacity of gypsum slurry during high load [6].

- Appropriately reducing the air flow and the flow rate of flue gas

“Gypsum rain” phenomenon is often seen during high load operations of boilers, which is related to the flue gas flow. When with a large load, under the premise of ensure the oxygen of daily boiler combustion, reducing the air flow appropriately and controlling hearth negative pressure and boostering fan pressure to reduce the gas flow and velocity.

\section{Conclusions and Recommendations}

For that most local coal-fired power plants adopt limestone/ gypsum wet FGD without installing the GGH, "gypsum rain” is easily induced by the low-temperature stack under the adverse condition of weather, polluting the environment and the surroundings of power plants. In combination with the actual circumstances of coal-fired power plant, we put forward the following recommendations.

- All the local coal-fired power plants facilities which adopted wet desulphurization without GGH should strengthen the optimized operation and management 
so as to reduce the influence of the gypsum rain.

- For the exit coal-fired units without GGH in nearby areas, a check should be done to the Desulphurization facilities defogger. In the mean time, carrying out a technological transformation on the desulfurization facilities whose effect of defogger is not ideal. Taking measures like adding a gas heater or hot air into the boiler equipment for reconstruction project in order to lift the temperature of flue gas and cut from the source "gypsum Rain” production.

- While modifying the desulphurization facilities of the coal-fired units, an effective control should be taken to "gypsum Rain" as one of the keys of pollution controlling. It is required that a GGH and other gas heating facilities should be installed simultaneously. All the above-mentioned measures are aimed to avoid "gypsum rain" phenomenon.

\section{REFERENCES}

[1] CHENG Yong-xin. Analysis and Countermeasure to "gypsum rain” problem of wet flue gas desulfurization system [J]. central China electric power, vol.23 , page:27-30, 2010.

[2] Ye chao, Zhang ran. Set Analysis of advantages and disadvantages of the flue gas heat exchanger [J]. Shanghai electric power, vol.5, page: 466- 468, 2006.

[3] Zhao Penggao, Ma Guojun, Wang Baode, etc. Discussion on flue gas heater of limestone-gypsum wet FGD [J]. Electric power environmental protection, vol.21, no.4, page: 19-21, 2005.

[4] Wang Yifang, Liu Wanju, Zhang bing. Technical analysis on GGH setting in desulfurization system [J]. Technology communion, vol.34, no.3, page:47-48, 2006.

[5] Eliminate design and optimization of gypsum rain [J]. Low carbon, page: 70-80, 2010.

[6] FU Yu , He Jinqi, Discussion about solution of gypsum rain when wet desulphurization used for power plant[J], Heilongjiang Electric Power, vol.31, no.5, page:374-376, 2009. 